\title{
EDUCANDO PARA O DESENVOLVIMENTO SUSTENTAVEL POR MEIO DA INTER- DISCIPLINARIDADE: CONTRIBUIÇÕES DA APRENDIZAGEM EXPERIENCIAL NO ENSINO DE GESTÃO
}

\author{
EDUCATING FOR SUSTAINABLE DEVELOPMENT THROUGH INTERDISCIPLI- \\ NARITY: CONTRIBUTIONS OF EXPERIENTIAL LEARNING IN MANAGEMENT \\ EDUCATION
}

Recebido em: 25/03/2019 - Aprovado em: 09/08/2019

Avaliado pelo sistema double blind review

Editora Científica convidada: Patricia Kanashiro

DOI 10.13058/raep.2019.v20n3.1463

\section{NATHÁLIA RIGUI TRINDADE nathaliariguitrindade@gmail.com MARCELO TREVISAN \\ ÉRICA SANTINI DE LIMA RODRIGO REIS FAVARIN}

Universidade Federal de Santa Maria

\begin{abstract}
RESUMO
Cessar a reprodução dos atuais problemas sociais, ambientais e econômicos exige uma transformação da maneira de abordar a educação e a vida, o que evidencia a importância da educação para a sustentabilidade (EpS). Ao analisar a formação de profissionais de gestão, a importância da EpS fica ainda mais manifesta, considerando os impactos das decisões desses profissionais sobre o meio ambiente e sociedade. Assim, para que objetivos da EpS sejam alcançados, novas propostas pedagógicas são necessárias, a EpS encontra oportunidades nas abordagens de aprendizagem de epistemologia construtivista, como a aprendizagem experiencial (AE). Assim, a presente pesquisa tem como objetivo analisar a capacidade contributiva da aprendizagem experiencial para a educação para a sustentabilidade em uma iniciativa interdisciplinar desenvolvida no ensino de gestão. A partir da realização de entrevistas e aplicação de questionário, levantou-se dados a respeito da iniciativa interdisciplinar, composta por duas disciplinas (Projeto Interdisciplinar 1 e 2) e sua relação com a AE. Os resultados indicam que ao adotar a $\mathrm{AE}$ como pano de fundo para o desenvolvimento da iniciativa é possível alcançar os resultados almejados pela EpS, contribuindo com o desenvolvimento discente no que tange ao pensamento crítico, visão sistêmica, perspectiva de futuro, entre outros. Palavras-chave: Educação para a sustentabilidade. Aprendizagem experiencial. Educação profissional e tecnológica. Ensino de Gestão e Negócios.
\end{abstract}

\footnotetext{
ABSTRACT

Ceasing the reproduction of current social, environmental and economic problems requires a transformation of the way of approaching education and life, which highlights the importance of education for sustainability (EfS). When analyzing the training of management professionals, the importance of EfS becomes even higher, considering the impacts of their decisions on the environment and society. Thus, for EfS objectives to be achieved, new pedagogical proposals are needed, in this way EfS finds opportunities in constructivist epistemology learning approaches, such as experiential learning (EL). Thus, this research aims to analyze the contributory capacity of experiential learning for EfS in an interdisciplinary initiative developed in management education. Data were raised about an interdisciplinary initiative, composed of two disciplines (Interdisciplinary Project 1 and 2) and its relationship with EL, through interviews and the application of a questionnaire. The results indicate that by adopting EL as a background for the development of the initiative, it is possible to achieve the results sought by EfS. It can contribute to student development regarding critical thinking, systemic vision, future perspective, among others.

Keywords: Education for sustainability. Experiential learning. Professional and technological education. Management and business teaching.
} 


\section{INTRODUÇÃO}

Cada vez mais torna-se necessário soluções inovadoras que proporcionem o crescimento econômico, bem-estar e equidade social e, que levem em consideração o meio ambiente com suas necessidades e limitações. Em 2015, as Nações Unidas, em conjunto aos governos, sociedade civil e outros parceiros, elaboraram uma agenda de desenvolvimento pós-2015, a Agenda 2030. Nessa Agenda, os países tiveram a oportunidade de adotar a nova agenda de desenvolvimento sustentável e chegar a um acordo global sobre a mudança climática e demais desafios da sustentabilidade. O texto final da Agenda 2030 propõe 17 Objetivos de Desenvolvimento Sustentável (ODS) e 169 metas para o desenvolvimento sustentável (ONU, 2015).

Mediante os objetivos propostos, este trabalho relaciona-se especialmente com o objetivo 4 - assegurar a educação inclusiva e equitativa e de qualidade e promover oportunidades de aprendizagem ao longo da vida para todos. Esse aspecto pode ser importante tanto para apoiar o desenvolvimento de sociedades inovadoras e baseadas no conhecimento, quanto para resolver os atuais desafios globais e fazer progressos no desenvolvimento sustentável (COLGLAZIER, 2015). Desta forma, considera-se essencial para o alcance do desenvolvimento sustentável, educar com um propósito de fomentar pensamentos e conhecimentos em direção à sustentabilidade, tornando-a centro do processo educacional, no qual os alunos, por meio de uma abordagem interdisciplinar, possam não só aprender sobre os desafios da sustentabilidade, mas também desenvolver capacidades para tornarem-se agentes de mudança na legitimação do desenvolvimento sustentável (ROWE, 2007).

Para Leal Filho (2015) a educação para o desenvolvimento sustentável (EDS) busca incentivar a construção de consciência sobre as quatro perspectivas que envolvem o desenvolvimento sustentável - ecológica, política, social e econômica - por meio de um processo educativo que se utiliza de métodos e abordagens de ensino específicas. Apesar de não haver consenso na literatura sobre as definições conceituais dos termos educação para a sustentabilidade e educação para o desenvolvimento sustentável, ha- 
vendo diferenças epistemológicas, destaca-se que neste estudo assume-se os mesmos como sinônimos, ao considerar a sustentabilidade como consequência do desenvolvimento sustentável.

Na Agenda 2030, no campo específico da educação de adultos há destaque para o papel da Educação e Formação Técnica e Profissional na promoção da sustentabilidade (ONU, 2015). O que revela a importância de transformar a formação tecnicista dos negócios em uma voltada para formação de profissionais com visão ampliada e comprometida com os desafios da sustentabilidade, em todos os níveis e modalidades de ensino.

Com isso, tornar a sustentabilidade internalizada na formação de futuros gestores revela-se como um subsídio relevante para uma tomada de decisão consciente por parte do indivíduo (SILVA et al., 2013), considerando os impactos significativos sobre o meio ambiente físico e social das decisões destes profissionais. É por isso que um dos principais desafios da educação para a sustentabilidade (EpS) é educar indivíduos além de seus papéis profissionais e gerenciais, tendo em vista os desafios que a humanidade enfrenta e enfrentará, sendo uma responsabilidade extra para o ensino da administração se reinventar (JACOBI; RAUFFLET; ARRUDA, 2011).

Diante disso, a EpS requer métodos de ensino e aprendizagem participativos que motivem e capacitem os alunos a mudar seu comportamento e agir para o desenvolvimento sustentável (CARS; WEST, 2014). Neste sentido, para alguns autores a aprendizagem experiencial (AE) é uma das formas mais eficazes de promover mudanças positivas em indivíduos e organizações (BADEN; PARKES, 2013; UNESCO, 2017; CORSCADDEN; KEVANY, 2017).

A partir da perspectiva da EpS, a AE torna-se importante por envolver os alunos, desenvolvendo seu pensamento crítico, capacidade de resolução de problemas e tomada de decisão em contextos que são de seu interesse (UNESCO, 2017). Além disso, uma das características da AE consiste na ação reflexiva, que é muito importante quando se trabalha a sustentabilidade. Conforme Tilbury (2011), o pensamento reflexivo crítico na EpS é um processo que envolve um exame profundo das causas da insustentabilidade 
e possibilita aos aprendizes reconhecer o viés e as suposições subjacentes aos seus próprios conhecimentos, perspectivas e opiniões.

Tendo em vista o panorama apresentado, define-se o objetivo do presente trabalho analisar a capacidade contributiva da aprendizagem experiencial para a educação para a sustentabilidade em uma iniciativa interdisciplinar desenvolvida no ensino de gestão. Isso torna-se relevante uma vez que Brunnquell, Brunstein e Jaime (2015) afirmam que na área de gestão e negócios o objetivo da EpS é garantir que os alunos considerem, em seus processos de tomada de decisão, não apenas questões econômicas, mas principalmente questões ambientais, sociais, culturais e éticas, e que se tornarem participantes ativos na construção de uma sociedade mais justa.

Além disso, para Leal Filho (2015) há uma escassez de estudos que documentem e promovam iniciativas bem-sucedidas de EpS, de modo a inspirar outras. Assim, a presente pesquisa busca contribuir com a consolidação da $\mathrm{AE}$ como ferramenta na promoção da $\mathrm{EpS}$, tendo em vista que na literatura são encontradas poucas pesquisas que investigam o papel que a aprendizagem experiencial pode desempenhar na EpS (WRIGHT, 2006).

Para a operacionalização do alcance do objetivo proposto, o estudo caracteriza-se como qualitativo, do tipo exploratório, adotando o estudo de caso como estratégia de pesquisa. Como fonte de coleta de dados foram utilizadas a pesquisa documental, entrevistas semiestruturadas com os docentes diretamente envolvidos com a iniciativa, observação participante e questionários, que foram aplicados com os alunos.

Desta maneira, o artigo encontra-se estruturado em seis seções, sendo esta introdução a primeira delas. Na sequência, a segunda seção resgata os principais conceitos e literatura sobre os temas educação para a sustentabilidade e aprendizagem experiencial. Já, na terceira seção o percurso e procedimentos metodológicos utilizados para realização da pesquisa são apresentados. Assim, na quarta seção apresenta-se os resultados obtidos com o estudo que, logo, são discutidos na quinta seção. Por fim, na última seção são apresentadas as considerações finais do estudo. 


\section{EDUCAÇÃO PARA A SUSTENTABILIDADE}

O conceito do desenvolvimento sustentável (DS) popularizou-se a partir do Relatório Brundtland - "Nosso Futuro Comum" em 1983, criado pela Comissão Mundial para o Meio Ambiente e o Desenvolvimento (CMMAD). Em 2002, a Cúpula Mundial sobre DS, expandiu a sua definição padrão com os três pilares amplamente utilizados do desenvolvimento sustentável: econômico, social e ambiental (KATES et al., 2005). O que Elkington (1999) denominou de Triple Bottom Line, o tripé da sustentabilidade, modelo de mudança social que parte da ideia de que as organizações devem medir o valor que geram, ou o que destroem, nas dimensões econômica, social e ambiental. A partir do avanço dos estudos acerca do tema, Ignacy Sachs inclui em sua definição de DS mais algumas dimensões, sendo elas: social, ecológica, ambiental, econômica, política nacional, política internacional, cultural e territorial (SACHS, 2002). Assim, Sachs (2002) deixa claro que, para alcançar a sustentabilidade, é necessário valorizar as pessoas, seus costumes e saberes.

Neste sentido, ao buscar reflexões e respostas sobre a realidade, a educação é vista como uma peça fundamental para que as práticas insustentáveis sejam modificadas (FIGUEIRÓ; RAUFFLET, 2015). Reforçando, Dubey, Gunasekaran e Deshpande (2017, p.34) defendem que "a conscientização pública, a educação e o treinamento são fundamentais para mover a sociedade em direção à sustentabilidade". Em 2005, a UNESCO lança a iniciativa "A Década da Educação para o Desenvolvimento Sustentável (DEDS)", caracterizando a EpS como uma educação de qualidade, que deve ser: holística e multidisciplinar; visar à aquisição de valores; estimular o processo participativo de tomada de decisão; estar estreitamente relacionada com a vida local; desenvolver o pensamento crítico e capacidade de resolução de problemas; recorrer à multiplicidade de métodos e; ser aplicável.

Além disso, a Agenda 2030 para o desenvolvimento sustentável estabelece objetivos e metas agrupados em áreas consideradas pela ONU (2015) de importância crucial para a humanidade e para o planeta, sendo elas: pessoas, planeta, prosperidade, paz e parceria. Para alcançar sucesso 
nos ODS, Colglazier (2015) focaliza três questões principais: (i) usar o processo do Relatório de Desenvolvimento Sustentável Global (GSDR) - que possui o papel de acompanhamento e revisão da Agenda 2030 - para unir os ODS e as comunidades científicas, (ii) escolher metas, indicadores e roteiros relacionados com ciência, tecnologia e inovação e, (iii) o imperativo de construir sociedades baseadas no conhecimento.

É notável, então, que para alcançar a sustentabilidade, é de suma importância pensar em estratégias de educação para a sustentabilidade, tendo em vista o que "o nosso maior legado para as futuras gerações, além de evitar guerras e conflitos, pode estar em construir sociedades baseadas no conhecimento e acelerar a expansão do conhecimento científico e de tecnologias úteis" (COLGLAZIER; 2015, p.1050). Em vista disso, o quarto objetivo da Agenda (Educação de Qualidade) busca assegurar a educação inclusiva, equitativa e de qualidade, e promover oportunidades de aprendizagem ao longo da vida para todos. Conforme o texto da Agenda, a educação torna-se peça-chave uma vez que a "promoção da capacitação e empoderamento dos indivíduos é o centro deste objetivo, que visa ampliar as oportunidades das pessoas mais vulneráveis no caminho do desenvolvimento" (ONU, 2015).

Cars e West (2014) percebem que a natureza da EpS é interdisciplinar e trata do respeito em múltiplas dimensões. Para os autores, a EpS permite que todo indivíduo adquira conhecimentos, habilidades, atitudes e valores necessários para moldar o futuro sustentável. Isso exige métodos participativos de ensino e aprendizagem que motivem e capacitem os alunos a mudarem seus comportamentos e a tomarem atitudes em prol do DS. Assim, a EpS promove competências como o pensamento crítico, de forma a prever cenários futuros e tomar decisões de maneira colaborativa (CARS; WEST, 2014).

Do mesmo modo, Jacobi, Raufflet e Arruda (2011) afirmam que as ações de EpS devem ser baseadas em abordagens pedagógicas que objetivem a criticidade, a mudança de atitudes e comportamentos, a participação de toda a sociedade e o desenvolvimento de organizações sociais. Desta forma, a integração da sustentabilidade no ensino está estritamente atrelada 
ao desenvolvimento de conhecimento, capacidades e habilidades emancipatórias, de maneira a possibilitar aos alunos as condições necessárias para a compreensão e transformação do mundo (WALS; JICKLING, 2002).

Porém, a implementação da sustentabilidade nas instituições de ensino enfrenta diversos desafios, Jacobi, Raufflet e Arruda (2011) destacam três principais: i) enfoque fragmentado da sustentabilidade, não abordando com profundidade todas as dimensões necessárias; ii) organização por disciplinas nas universidades, o que dificulta a promoção da interdisciplinaridade (condição necessária para a EpS), sendo necessárias novas abordagens de ensino e aprendizagem, como a aprendizagem experiencial e; iii) processo organizacional dentro das instituições, que deve abordar a sustentabilidade de maneira ampla e sistêmica, de forma a envolver todos os stakeholders. Conforme os autores, as experiências e práticas educativas desta nova maneira de educação ainda são recentes e incipientes, o que torna imprescindíveis ações que visem estimular a interação e interdependência entre as disciplinas e entre as pessoas, buscando o desenvolvimento de novas metodologias interativas de ensino.

Down (2006) aborda, em seu estudo, os principais desafios da integração da EpS no currículo. Dentre os desafios, o autor destaca o envolvimento da equipe na reorientação do curso para abordar a sustentabilidade, a partir da necessidade de sensibilização para reconhecimento da legitimidade da questão e do desenvolvimento de uma abordagem pedagógica holística e interdisciplinar. Além disso, destaca o desafio de fazer com que a EpS deixe de ser uma iniciativa pessoal, de um docente, e passe a ser tratada como uma política dentro das instituições de ensino. Esse processo é lento e deve ser contínuo, a partir da construção de diálogo entre os docentes e conselhos escolares, trabalhando com conceitos e programas de educação ambiental e campanhas de atitudes e valores voltados à sustentabilidade.

Corroborando, Thomas, Hergarty e Holdsworth (2012) identificam alguns inibidores chave da EpS como: falta de compreensão e de formação para os acadêmicos; natureza da sustentabilidade impugnada; currículo lotado; demanda de tempo e recursos para a disseminação de conhecimentos e desenvolvimento de habilidade para a comunidade acadêmica e; culturas 
e premissas disciplinares. Para os autores, não existe uma ação clara que seja capaz de remover estes inibidores, o que existe é uma série de elementos que precisam se encaixar, como um quebra-cabeça, para auxiliar na implementação da EpS em uma determinada universidade.

Brunnquell, Brunstein e Jaime (2015) afirmam que na área de gestão e negócios o objetivo da EpS é garantir que os alunos considerem, em seus processos de tomada de decisão, não apenas questões econômicas, mas principalmente questões ambientais, sociais, culturais e éticas, e que se tornem participantes ativos na construção de uma sociedade justa. Assim, Vasconcelos, Junior e Silva (2013, p.56) afirmam que a educação gerencial no contexto da sustentabilidade é um processo socialmente construído que demanda "um conjunto de mudanças que abrange a reforma curricular no sentido mais amplo, implicando a alteração da abordagem e do lócus da aprendizagem, na frequência, nas metodologias, nos conteúdos e nos processos utilizados".

Conforme estudo realizado por Berchin et al. (2018), as abordagens inter e multidisciplinares são indicadas pela literatura científica, bem como pelos tópicos das conferências investigadas na pesquisa, como essenciais para a sustentabilidade, uma vez que fornecem uma visão holística sobre a temática. Jiji et al. (2015) afirmam que relações interdisciplinares, de diálogo e integração entre os componentes curriculares de diversas áreas do conhecimento são essenciais para que projetos em sustentabilidade obtenham sucesso. Isto, pois, conforme Howlett, Ferreira e Blomfield (2016) uma abordagem interdisciplinar, se concentra na promoção de diferentes formas de olhar o mundo, incentivando a autonomia, autodeterminação, pensamento crítico, capacidade reflexiva e o desenvolvimento do que poderia ser chamado de "consciência planetária".

Assim, buscando trabalhar com a interdisciplinaridade e com abordagens mais práticas, dentro da perspectiva da EpS, uma oportunidade é o desenvolvimento da aprendizagem experiencial (JACOBI; RAUFFLET; ARRUDA, 2011), foco da próxima seção. 


\section{Teoria da Aprendizagem Experiencial e Eps}

A partir do exposto, indica-se que a EpS requer não apenas aprendizagem instrumental, mas também uma que atente para as mudanças de percepção, valores e atitudes dos alunos. O que exige a implementação de metodologias ativas em sala de aula que aproximem os alunos da realidade do seu entorno (BRUNNQUELL; BRUNSTEIN; JAIME, 2015). Brundiers e Wiek (2013) destacam que a literatura enfatiza o potencial das abordagens de aprendizagem colaborativa, contextuais e construtivistas no desenvolvimento de possíveis soluções para problemas de sustentabilidade do mundo real, sendo as mais indicadas para a capacitação dos alunos em matéria de sustentabilidade.

Para Howlett, Ferreira e Blomfield (2016) abordagens de aprendizagem construtivistas partem do pressuposto de que os alunos aprendem melhor quando eles estão envolvidos ativamente na construção do conhecimento, em um quadro de suas próprias experiências, ao invés de receber passivamente informações transmitidas por livros ou professores.

Ainda, Tilbury (2011) indica que os processos de aprendizagem ativos e participativos são percebidos como os mais apropriados para a aprendizagem da EpS. Para o autor, a aprendizagem ativa e participativa incentiva os alunos a: i) fazer perguntas reflexivas e críticas; ii) esclarecer valores; iii) projetar futuro mais positivo; iv) pensar sistematicamente; v) responder por meio da aplicação da aprendizagem e; vi) explorar a dialética entre tradição e inovação, o que faz com que essas sejam comumente consideradas um dos principais processos subjacentes à EpS.

Dentro das abordagens alinhadas com os objetivos da aprendizagem ativa, encontra-se a aprendizagem experiencial (AE) de Kolb (1984). O autor apresenta seis principais proposições sobre a TAE, conforme a Figura 1. 
Figura 1 Proposições sobre a Teoria da Aprendizagem experiencial

\begin{tabular}{|c|c|}
\hline Proposição & De \\
\hline $\begin{array}{l}1 \text { - A aprendizagem é mais } \\
\text { bem concebida como um } \\
\text { processo, e não em termos } \\
\text { de resultados. }\end{array}$ & $\begin{array}{l}\text { O conhecimento é um processo de transforma- } \\
\text { ção, que permite que os homens alterem suas } \\
\text { visões de mundo a partir de suas experiências. }\end{array}$ \\
\hline $\begin{array}{l}2 \text { - Todo o aprendizado é um } \\
\text { reaprendizado. }\end{array}$ & $\begin{array}{l}\text { O conhecimento é derivado e testado constan- } \\
\text { temente nas experiências dos indivíduos. E esse } \\
\text { processo é contínuo. }\end{array}$ \\
\hline $\begin{array}{l}3 \text {-A aprendizagem requer a } \\
\text { resolução de conflitos entre } \\
\text { modos de adaptação dialeti- } \\
\text { camente opostos. }\end{array}$ & $\begin{array}{l}\text { No processo de aprendizagem, o aluno é cha- } \\
\text { mado a transitar entre modos opostos de refle- } \\
\text { xão e ação, sentimento e pensamento . }\end{array}$ \\
\hline $\begin{array}{l}4 \text { - Aprendizagem é um pro- } \\
\text { cesso holístico de adaptação. }\end{array}$ & $\begin{array}{l}\text { A aprendizagem envolve as funções integradas } \\
\text { de todo o organismo, não se limitando a uma } \\
\text { única ou algumas poucas funções humanas, tais } \\
\text { como cognição ou percepção. }\end{array}$ \\
\hline $\begin{array}{l}5 \text { - Aprendizagem envolve } \\
\text { transações sinérgicas entre as } \\
\text { pessoas e o meio ambiente. }\end{array}$ & $\begin{array}{l}\text { A relação transacional entre as pessoas e o meio } \\
\text { ambiente implica em um relacionamento mais } \\
\text { fluido, interpenetrado, entre as condições sub- } \\
\text { jetivas e objetivas da experiência. }\end{array}$ \\
\hline $\begin{array}{l}6 \text { - Aprendizagem é o proces- } \\
\text { so de criar conhecimento. }\end{array}$ & $\begin{array}{l}\text { Conhecimento é o resultado da transação entre } \\
\text { conhecimento social e conhecimento pessoal. }\end{array}$ \\
\hline
\end{tabular}

Fonte: Elaborado com base em Kolb (1984).

No processo de aprendizagem, Kolb (1984) destaca a dialética reflexiva/ativa, que consiste em duas formas opostas de transformar a apreensão ou "representação figurativa" da experiência: i) reflexão interna, chamada de intenção, pelo qual o aluno busca refletir sobre o conhecimento adquirido anteriormente e; ii) manipulação externa e ativa do mundo externo, chamado de extensão, que requer que o indivíduo interaja com o ambiente externo (KOLB, 1984; KOLB; KOLB, 2005). Assim, para Kolb (1984) o processo de AE compreende um ciclo de quatro etapas, conforme Figura 2. 
Figura 2 Ciclo de aprendizagem experiencial

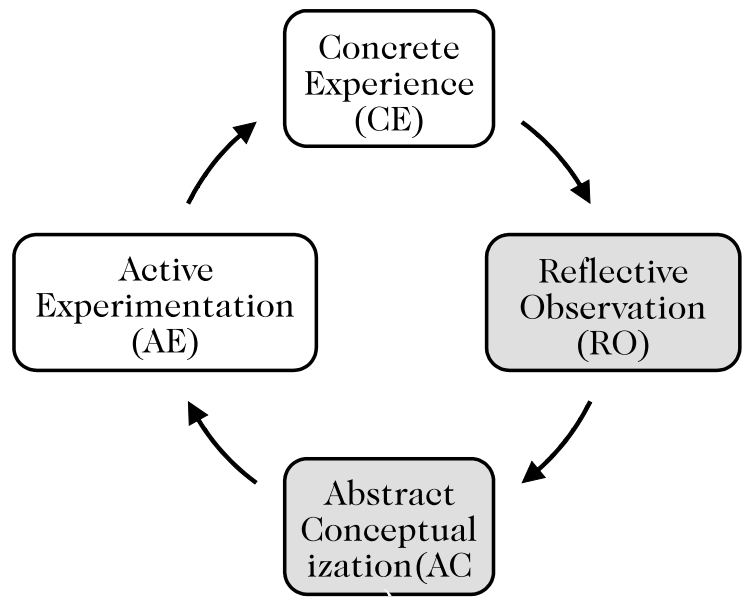

Fonte: Adaptado de Young (2002).

Neste ciclo, observa-se a experiência concreta (EC), no qual há o envolvimento por completo e sem viés dos alunos em novas experiências Em seguida, a observação reflexiva (OR) que consiste na reflexão e observação de suas experiências, a partir de diversas perspectivas. Após, a conceituação abstrata (CA) que envolve a capacidade de criar conceitos que integrem suas observações em teorias. E, finalmente, essas teorias devem ser utilizadas para a tomada de decisão e resolução de problemas na experimentação ativa (EA) (ALVES; TOMETICH, 2016).

Vale destacar que, neste estudo, o modelo conceitual para aprendizagem experiencial desenvolvido por Krakauer, Serra e Almeida (2017) foi adotado, tendo em vista que o modelo Kolb (1984) foi desenvolvido para estudantes de pós-graduação e o modelo de Krakauer, Serra e Almeida (2017), conforme Figura 3, foi adaptado para estudantes de graduação, se aproximando mais da realidade de um curso técnico, foco desta pesquisa. 
Figura 3 - Modelo conceitual aprendizagem experiencial

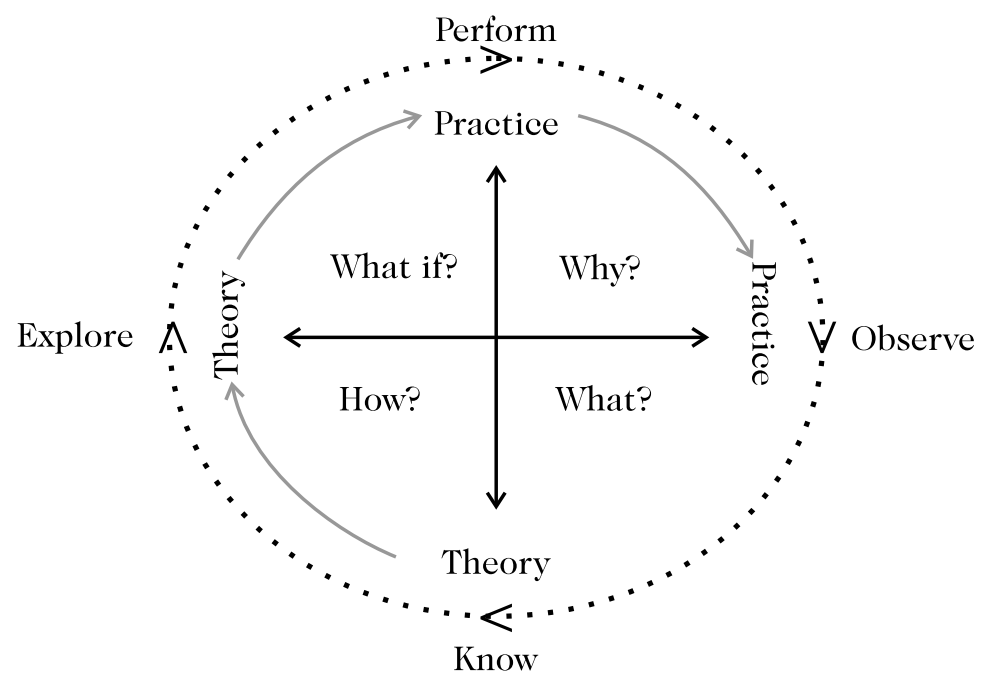

Fonte: Krakauer, Serra e Almeida (2017).

Conforme Krakauer, Serra e Almeida (2017), o modelo resguarda o preconizado por Kolb (1984) somado aos estudos de Sharlanova (2004) e incorpora elementos de Belhot (1997), incorporando os quadrantes "Por quê?”, "O quê?", "Como?” e "E se?”. Desta forma, as quatro etapas principais do ciclo de AE são repensadas, haja vista que o mesmo passa a considerar não somente experiências concretas, mas principalmente as experiências substitutivas para a realidade dos alunos, já que a maioria não possui experiência profissional fora da academia. 


\section{MÉTODO}

A partir do objetivo proposto - analisar a capacidade contributiva da aprendizagem experiencial para a educação para a sustentabilidade em uma iniciativa interdisciplinar desenvolvida no ensino de gestão - é possível definir como método de investigação a pesquisa qualitativa, do tipo exploratória, adotando o estudo de caso como estratégia de pesquisa.

Conforme Sampieri, Collado e Lucio (2013), a pesquisa qualitativa objetiva a compreensão acerca dos fenômenos explorados a partir da perspectiva dos participantes, aprofundando suas experiências, seus pontos de vista, opiniões e significados sobre a subjetividade de sua realidade. No que tange ao caráter exploratório da pesquisa, justifica-se por buscar examinar um tema pouco estudado, sobre o qual se tem muitas dúvidas ou ainda não foi abordado (SAMPIERI; COLLADO; LUCIO, 2013). Além disso, como estratégia, o estudo de caso é adotado na presente investigação em função de "investigar um fenômeno contemporâneo dentro de seu contexto da vida real, especialmente quando os limites entre o fenômeno e o contexto não estão claramente definidos" (YIN, 2015, p. 32).

A unidade de análise definida constitui-se no Curso Técnico em Administração Integrado ao Ensino Médio do Instituto Federal de Educação, Ciência e Tecnologia do Rio Grande do Sul (IFRS) do campus de Canoas. Participaram da pesquisa quatro docentes do Curso Técnico em Administração integrado ao Ensino Médio do campus Canoas e quarenta e cinco alunos, dos quais vinte e cinco participavam da disciplina Projeto Interdisciplinar 1 (PI 1) e vinte da Projeto Interdisciplinar 2 (PI 2). Os docentes foram denominados E1, E2, E3 e E4; os discentes da disciplina PI 1 como A1, A2, A3, etc. e os discentes da disciplina PI 2 como B1, B2, B3, etc.

Como fonte de coleta de dados, foram utilizadas a pesquisa documental, entrevistas semiestruturadas com os docentes diretamente envolvidos com a iniciativa, observação participante e questionários, que foram aplicados aos alunos. Segundo Yin (2015) a confiabilidade de um estudo de caso, poderá ser garantida por meio da utilização de diversas fontes de evidências. O processo de triangulação garante que descobertas, neste tipo 
de estudo, sejam convincentes e acuradas, de forma a possibilitar um estilo corroborativo de pesquisa.

Para o desenvolvimento da pesquisa documental foram coletados documentos vinculados à unidade de análise, como o Projeto Político Pedagógico do Curso Técnico em Administração integrado ao Ensino Médio do campus Canoas e os planos de ensino das disciplinas Projeto Interdisciplinar 1 e 2 . As entrevistas foram realizadas com quatro docentes envolvidos diretamente com as disciplinas Projeto Interdisciplinar 1 e 2, conforme Figura 4.

Figura 4 Sujeitos entrevistados no estudo

\begin{tabular}{|c|c|}
\hline $\begin{array}{l}\text { Entre- } \\
\text { vistado }\end{array}$ & Descrição \\
\hline E1 & $\begin{array}{l}\text { Professor que era responsável pela disciplina no período anterior à } \\
\text { pesquisa. Área de formação: Administração. }\end{array}$ \\
\hline E2 & $\begin{array}{l}\text { Professora responsável pela disciplina no período da pesquisa. Área } \\
\text { de formação: Administração. }\end{array}$ \\
\hline E3 & $\begin{array}{l}\text { Coordenadora do Curso Técnico em Administração integrado ao } \\
\text { Ensino Médio no período de realização da pesquisa. Área de for- } \\
\text { mação: Direito. }\end{array}$ \\
\hline E4 & $\begin{array}{l}\text { Professora que era coordenadora do Curso Técnico em Adminis- } \\
\text { tração integrado ao Ensino Médio no período anterior à realização } \\
\text { da pesquisa. Área de formação: Química. }\end{array}$ \\
\hline
\end{tabular}

Fonte: Elaborado pelos autores.

Foram elaborados dois roteiros de entrevistas com base no objetivo de pesquisa e revisão da literatura. O primeiro, aplicado com os docentes que ministram a disciplina, composto por dois blocos: quanto aos elementos da aprendizagem experiencial e quanto aos componentes da educação para sustentabilidade. Já, o segundo, direcionado aos docentes de gestão, composto por apenas um bloco englobando o processo de aprendizagem de maneira geral com foco na AE. Todas as entrevistas foram gravadas e transcritas para posterior análise. 
Conforme Minayo (2004), na observação participante o pesquisador está presente na situação social observada, colhendo dados e fazendo parte do contexto em observação. A partir da presença do pesquisador no campus e em algumas aulas das disciplinas pesquisadas, realizou-se anotações em um diário de campo no que tange aspectos relacionados com os princípios da EpS e da AE.

Além disso, conforme mencionado, coletaram-se dados com os discentes a partir da aplicação de questionários. Esses foram aplicados em período de aula e tinham como objetivo fazer o levantamento de dados do perfil dos estudantes, do conhecimento prévio que os mesmos tinham sobre sustentabilidade e sua percepção a respeito da inserção da temática sustentabilidade no ensino de gestão. O questionário era composto de onze perguntas, sendo seis questões referentes ao perfil, três questões sobre conhecimento prévio da temática sustentabilidade (uma questão fechada e duas abertas) e duas questões sobre a inserção da sustentabilidade no ensino de gestão (fechadas com espaço para justificar a resposta dada). De posse dos dados, os mesmos foram tabulados e organizados no software Microsoft Excel para posterior análise.

Com o objetivo de organizar e sumariar os dados obtidos, foi utilizada a técnica de análise de conteúdo (GIL, 2017). Desta forma, conforme Ferreira e Loguecio (2014), a análise de conteúdo relaciona-se com a manipulação do texto, interpretando-o com o objetivo de inferir os sentidos que extrapolam o seu conteúdo objetivo, indo além do que está nas manifestações informadas, identificando elementos subjetivos oriundos das condições de produção/recepção do conteúdo e das condições de produção da análise. A definição das categorias de análise foi realizada a priori, baseadas em dois quadros de referência teórica, sendo o primeiro referente aos componentes principais da EpS e o segundo baseado em Kolb (1984) com os seis pressupostos básicos da AE. Destaca-se, também, que estas categorias serviram de base para que a pesquisadora pudesse realizar registros e anotações no diário de campo durante a observação participante de maneira a sistematizar as experiências vivenciadas para posterior análise dos dados. 


\section{RESULTADOS}

Esta seção destina-se a apresentar os principais resultados obtidos com a pesquisa. Está estruturada de maneira a, inicialmente, apresentar os dados relativos à percepção docente tanto no que tange à educação para a sustentabilidade, quanto aos aspectos relacionados ao processo de aprendizagem. Na sequência, discorre sobre os achados relacionados aos discentes envolvidos na iniciativa estudada.

\section{Entrevista com professores}

Esta análise está pautada em documentos da Instituição e nas entrevistas realizadas com os quatro docentes diretamente envolvidos com as disciplinas Projeto Interdisciplinar. Assim, incialmente, apresenta-se a iniciativa interdisciplinar estudada e, posteriormente, divide-se a análise em duas categorias: i) educação para a sustentabilidade e; ii) processo de aprendizagem.

O estudo foi realizado no Curso Técnico em Administração Integrado ao Ensino Médio do Instituto Federal de Educação, Ciência e Tecnologia Rio Grande do Sul (IFRS) - Campus Canoas. O Campus foi fundado em 25 de agosto de 2007 e teve suas aulas iniciadas em agosto de 2010. Ao analisar as finalidades e características dos Institutos Federais definidas pela Lei 11.892/2008 pode-se perceber uma preocupação com a formação de indivíduos críticos capazes de observar sua realidade e agir sobre ela por meio do ensino, da investigação empírica e da extensão (BRASIL, 2008).

Alinhado ao que é estabelecido na Lei 11.892/2008, o Campus Canoas do IFRS almeja o desenvolvimento de um processo de inserção do homem na sociedade de forma participativa, ética e crítica. Seguindo estes princípios, o Curso Técnico em Administração Integrado ao Ensino Médio do Campus Canoas, busca atender às demandas existentes na região por profissionais qualificados. No que tange o objetivo do curso, busca-se formar um profissional integrado às funções administrativas, bem como aos quatro eixos da Administração, com capacidades técnicas para exercer as funções e atividades inerentes à profissão. Também, é possível notar a 
preocupação com a formação de um sujeito autônomo, capaz de buscar constante aprimoramento e desenvolver-se criticamente para adaptar-se com flexibilidade às constantes mudanças de maneira humana, ética e cidadã (IFRS, 2012).

Ao observar os pressupostos curriculares do Curso, é possível perceber uma preocupação com o desenvolvimento e resolução de problemas socioeconômicos voltados para a particularidade da região na qual está inserido. Este aspecto demonstra uma sensibilização no que tange à valorização de questões locais, como cultura, economia e necessidades da comunidade. O que vai ao encontro de algumas prerrogativas da EpS que afirmam que o processo de aprendizagem dever estar estreitamente relacionado com a vida local (UNESCO, 2005).

Ainda, é possível perceber uma preocupação com a integração e diálogo entre os componentes curriculares das diversas áreas - área técnica (administração) e as três grandes áreas do conhecimento (códigos, linguagem e suas tecnologias; ciências humanas e suas tecnologias e; ciências da natureza, matemática e suas tecnologias). Estas relações interdisciplinares, conforme Jiji et al. (2015) são essenciais para que os projetos em sustentabilidade tenham sucesso. Esta preocupação também é evidenciada nas entrevistas, conforme demonstra a afirmação da docente $\mathrm{E} 4$ de que "a proposta teórica do que é um curso integrado é muito interessante, ela surge como uma proposta pra formação integral do sujeito, além da área técnica”. Ademais, no que tange à maneira como a sustentabilidade é abordada no projeto pedagógico, observam-se diversas menções à temática em todo o texto, abordando os três pilares - ambiental, social e econômico.

Tendo como princípio a preocupação com a necessidade de integração dos saberes, surgiram as disciplinas Projeto Interdisciplinar 1 e 2 como uma maneira de assegurar um espaço no qual os professores pudessem planejar em conjunto com as demais áreas de conhecimento atividades em comum, de maneira a viabilizar, por meio da metodologia de pesquisa, a integração entre a formação técnica e a formação básica dos alunos Isso vai ao encontro do que é defendido por Berchin et al. (2018) e Howlett, Ferreira e Blomfiel (2016) no que tange a interdisciplinaridade.. 
Para tanto, vislumbrando a interdisciplinaridade e o ensino voltado para a sustentabilidade, as disciplinas em questão estão estruturadas conforme Figura 5.

Figura 5 Estrutura Disciplinas Projeto Interdisciplinar

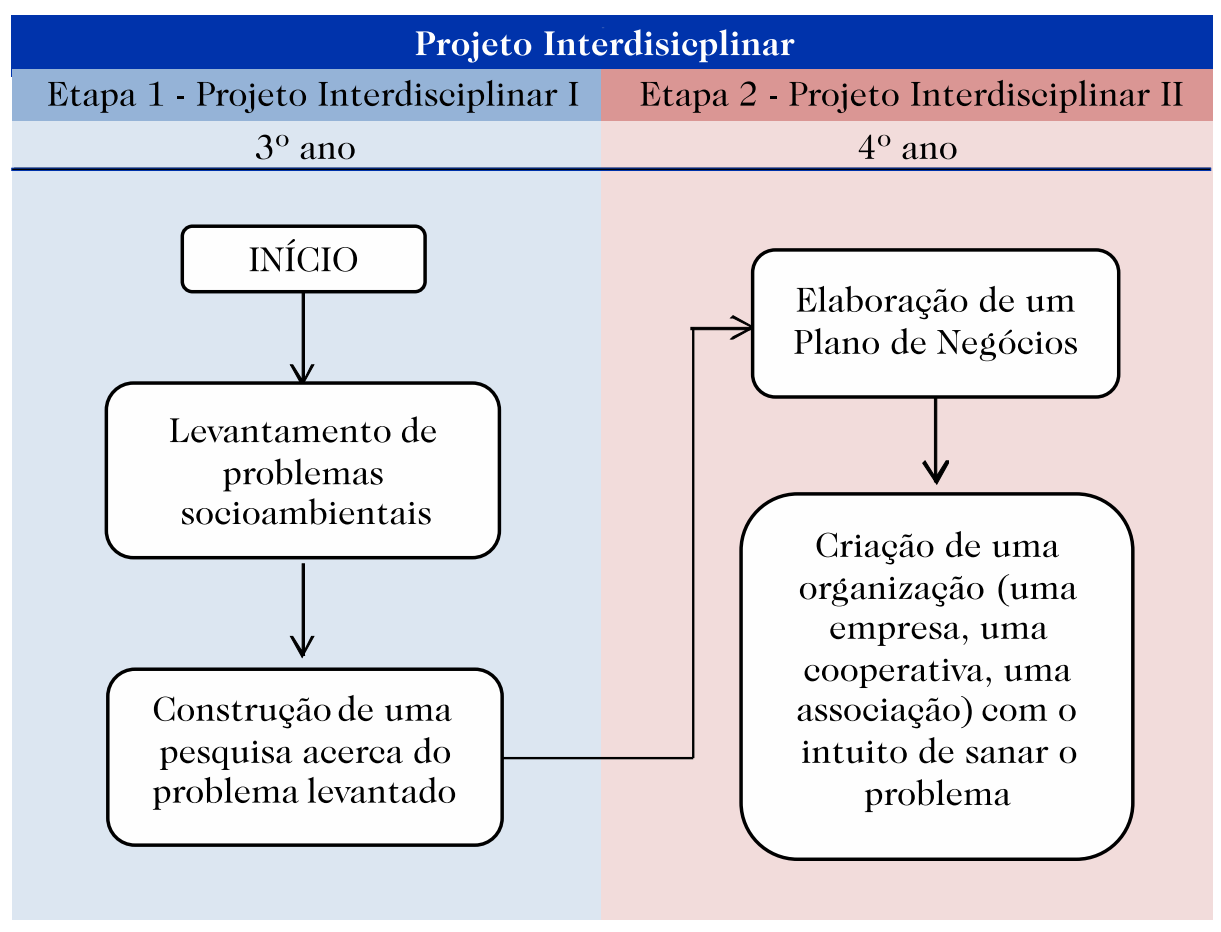

Fonte: Elaborado pelos autores com base em IFRS (2011).

As disciplinas Projeto Interdisciplinar buscam incentivar a pesquisa tanto para o levantamento dos problemas socioambientais existentes na região quanto para a proposta de soluções sustentáveis que promovam o equilíbrio econômico, social e ambiental (IFRS, 2011). Assim, conforme evidenciado na Figura 5, as disciplinas Projeto Interdisciplinar acontecem em duas etapas. A primeira etapa é desenvolvida com os alunos que estão cursando o terceiro ano do curso, na qual os estudantes devem levantar problemas socioambientais da sua região, para, posteriormente, no quarto ano desenvolver um plano de negócios de uma organização 
que busque minimizar os problemas identificados (PALMA; ALVES; SILVA, 2013).

Assim, as disciplinas Projeto Interdisciplinar 1 e 2 apresentam como tema central a sustentabilidade, reforçando a ideia de integração entre as diferentes disciplinas ao trabalhar conjuntamente com empreendedorismo coletivo, inovação social e sustentabilidade. Com isto, pretende-se integrar a teoria e a prática e, ao mesmo tempo, encorajar os estudantes a serem agentes ativos e transformadores da realidade, utilizando-se dos saberes construídos durante todo o curso para o exercício da cidadania e da prática profissional (IFRS, 2011). A partir das entrevistas, é possível perceber que a disciplina apresenta como foco fomentar a pesquisa e a integração curricular, integrando os conceitos de sustentabilidade.

Ao apresentar como objetivos: i) possibilitar aos estudantes compreenderem a relação sistêmica existente entre as organizações, a sociedade e o meio ambiente; ii) apresentar as características dos diferentes tipos de organizações, bem como do empreendedorismo individual e coletivo; iii) desenvolver a interdisciplinaridade e o senso crítico; iv) fomentar a Inovação Social e a construção de Organizações Inovadoras Sustentáveis, as disciplinas Projeto Interdisciplinar 1 e 2 representam uma importante ferramenta para que o Curso inclua questões relacionadas à EpS no currículo.

\section{Educação para a sustentabilidade}

Ao considerar que a educação para a sustentabilidade deve buscar três resultados principais, quais sejam: i) os estudantes devem ter conhecimento sobre questões de sustentabilidade; ii) devem ter habilidades para agir de forma sustentável se desejarem e; iii) devem desenvolver suposições, crenças e valores pessoais e emocionais que façam com que se comportem de maneira sustentável (CHALKLEY, 2006), esta seção busca evidenciar como a sustentabilidade é tratada dentro das disciplinas Projeto Interdisciplinar (PI 1 e PI 2) no que se refere a busca por estes resultados.

Inicialmente, no que tange ao conhecimento acerca de questões de sustentabilidade, é possível perceber que há uma grande preocupação em ofertá-lo aos alunos. A professora E2, responsável pelas disciplinas, ao rela- 
tar as atividades que estavam sendo desenvolvidas na época da entrevista, evidenciou a necessidade de apresentar temáticas relacionadas à sustentabilidade de maneira a legitimar e perpetuar uma visão de mundo mais ampla, que vá de encontro àquela vinculada a realidade instrumental e reducionista típica das organizações contemporâneas.

Com isto, a partir do processo ensino-aprendizagem adotado, almeja-se tornar os indivíduos auto conhecedores da sociedade e do mundo, buscando significado e questionando ideias e conceitos previamente conhecidos. Ou seja, o processo de ensino procura envolver um exame das causas da insustentabilidade e possibilitar aos aprendizes reconhecer o viés e as suposições subjacentes aos seus próprios conhecimentos, perspectivas e opiniões (TILBURY, 2011). Assim, ao dar ênfase no papel que as empresas e organizações assumem no desenvolvimento sustentável, a disciplina proporciona conhecimentos e estimula a análise crítica para que os estudantes de gestão possam repensar suas decisões enquanto consumidores e futuros profissionais.

Outrossim, Cars e West (2014) evidenciam que um dos pontos centrais da EpS é sua natureza interdisciplinar, sendo que a EpS deve se basear em abordagens pedagógicas que desenvolvam a criticidade dos estudantes, mudanças de atitudes e comportamentos, bem como a participação na sociedade e no desenvolvimento de organizações sociais (JACOBI; RAUFFLET; ARRUDA, 2011). Desta maneira, buscando atender a estas constatações, as atividades desenvolvidas na disciplina buscam incentivar os alunos a pensar em diferentes modelos de organizações, conforme evidenciado na manifestação da professora E2: "a ideia é que eles criem organizações que de fato tenham uma contribuição também pra sociedade, que tenham esse enfoque mais sustentável cuidando das questões econômicas, ambientais e sociais". Assim, a iniciativa busca expandir as visões dos alunos sobre as possibilidades de atuação de profissionais da área de gestão em consonância com os princípios e objetivos da sustentabilidade.

Por outo lado, algumas barreiras podem ser identificadas no processo de inserção da sustentabilidade na prática pedagógica, tendo em vista que para que isso possa ser realizado de maneira completa e faça parte das 
bases da educação gerencial para sustentabilidade, torna-se necessário uma revisão dos modelos já disseminados no mundo dos negócios (BOECHAT; GRASSI, 2005). Isso é retratado como uma dificuldade na afirmação da docente E2: "Eu tenho tido dificuldade pra [...] porque as ferramentas que eu tinha para o desenvolvimento de plano de negócio eram ferramentas um tanto quanto tradicionais”. Ainda, para que as experiências e práticas educativas obtenham sucesso ao abordar a sustentabilidade, são imprescindíveis ações que visem a interação e interdependência entre as disciplinas e entre as pessoas (JACOBI, RAUFFLET E ARRUDA, 2011). No entanto, dificuldades como a organização por disciplinas do currículo e a falta de compreensão dos docentes sobre a temática em si são inibidores identificados na iniciativa estudada.

Além disso, outro aspecto que merece destaque é a dependência que a disciplina apresenta no que tange o professor que a ministra, evidenciando uma ligação entre a promoção da EpS com os interesses de docentes específicos e a dificuldade enfrentada para que os educadores compreendam estas práticas educativas voltadas para a sustentabilidade. Essa realidade é retratada na fala: "O objetivo dessa disciplina que foi iniciada pela professora E2 num período em que eu não estava aí, e depois eu assumi a disciplina, depois de dois ou três professores terem tentado, mas não funcionava muito bem em função da falta de foco" (E1). Isso indica que todos os docentes, não apenas aqueles que atualmente ministram as disciplinas precisam estar conscientes da necessidade e da importância do tratamento de questões de sustentabilidade na disciplina. Assim, todos podem estar preparados e instrumentalizados para enfrentar os desafios, fazendo com que a perspectiva da sustentabilidade não se perca na iniciativa. Além do mais, as manifestações dos professores demonstram esse problema e outros como o currículo lotado e a alta demanda de tempo e recursos que inibem avanços no desenvolvimento de metodologias interativas para a disseminação da EpS.

O exposto reflete que a existência destas disciplinas garante um espaço para trabalhar com um projeto interdisciplinar que evidencia a relação entre a sustentabilidade e demais áreas do conhecimento. Isso configura-se como um começo bastante promissor em direção à presença transversal da 
temática, mas ainda há a necessidade de uma desfragmentação do currículo facilitando a visualização de como todas as áreas podem relacionar-se com a sustentabilidade. Esta constatação vai ao encontro da necessidade da adoção de métodos de ensino diferenciados que favoreçam o processo de aprendizagem dos estudantes. Na próxima seção, descreve-se como ocorre o processo de aprendizagem atualmente nas disciplinas à luz da AE.

\section{Processo de aprendizagem}

Assim como mencionado anteriormente, um dos desafios mais complexos para a EpS é abordar o tema de maneira interdisciplinar. Pensando nisto, a proposta das disciplinas Projeto Interdisciplinar 1 e 2 é adotar a metodologia de pesquisa para gerar uma nova perspectiva no processo de aprendizagem, sugerindo a colaboração e a interação entre professores, estudantes e comunidade. Conforme afirmação da professora E2, a pesquisa torna-se adequada uma vez que o aluno tem a oportunidade de "se apropriar do tema, pra entender um pouco mais sobre aquilo que eles trouxeram, como um problema do cotidiano deles" (E2).

Com isso, há um resgate de eventos da vida do aprendiz nas atividades proporcionadas no ensino formal. Espera-se, com isso, o desenvolvimento do pensamento independente e da reflexão crítica para a construção de novas visões de mundo, conforme evidenciado pela professora E2: "eles ampliarem um pouco a visão deles, aprender que a visão que eu tenho não necessariamente é o que acontece na realidade, eu posso estar enxergando as coisas de um ponto de vista que eu vivo naquele meu mundinho, mostrar através da pesquisa que eles podem começar a olhar as coisas de forma diferente". Pode-se, então, associar a manifestação da professora E2 ao que Kolb e Kolb (2005) afirmam de que o trabalho do educador não é apenas introduzir novas ideias, mas também trabalhar com a modificação de crenças e visões dos estudantes sobre uma temática que pode por eles ser examinada, testada e relacionada com novas ideias.

A AE de Kolb (1984) tem como uma de suas premissas que o processo de aprendizagem envolve a interação entre o indivíduo e o meio. Ao questionar como ocorre esta interação na iniciativa, a professora E2 eviden- 
ciou que a mesma acontece de maneira incipiente, uma vez que a interação, em maior parte, são limitadas a uma etapa específica do trabalho que é realizado durante a disciplina. Isso sugere que seria interessante pensar em diferentes estratégias que busquem uma maior interação do indivíduo com seu ambiente, fazendo com que o mesmo possa se sentir capaz de mudar a realidade em que vive.

De maneira complementar, esta preocupação é retratada na manifestação da professora E2 que afirma que "gostaria muito de trabalhar mais próximo da pesquisa ação e fazer com que eles tivessem intervenções nas realidades deles" . A entrevistada complementa afirmando que essa é uma abordagem mais difícil de ser desenvolvida pela demanda de tempo e pessoas para acompanhar os alunos fora do ambiente formal de ensino. $\mathrm{O}$ professor E1 também evidencia esta problemática ao afirmar que "Talvez se nós tivéssemos uma outra infraestrutura voltada para uma incubadora, algo assim [...] ainda continuo dizendo que não é falta de interesse deles (alunos) ou incompetência, muitas vezes, é falta de tempo tanto deles quanto nossa (professores)" (E1).

Outro aspecto que a $\mathrm{AE}$ destaca é que o aprendizado é um processo de adaptação do ser humano às mudanças do mundo, sendo essa uma concepção que vai além da sala de aula, envolvendo os vários estágios da vida humana, sua inteligência mental, comportamental e sentimental (KOLB, 1984; LEITE; GODOY; ANTONELLO, 2006). Quando questionados se percebiam o envolvimento por completo do estudante na experiência, ambos os professores E2 e E1 concordam que isso depende do perfil de cada turma, sendo que os alunos que estão cursando o quarto ano tornam-se menos envolvidos com o processo uma vez que estão com inúmeras atribuições de final do curso. Esse fato evidencia, mais uma vez, o impacto negativo do currículo lotado e da demasiada fragmentação curricular no desenvolvimento de uma pedagogia ativa de ensino.

Considerando que reflexão é elemento central no processo da aprendizagem experiencial, ao serem questionados sobre este aspecto, a professora E2 considera que há espaços informais para reflexão. No entanto, esses são limitados ao final da disciplina, não permeando todo o 
processo de aprendizagem. A professora E2 considera importante pensar em estratégias para inserir mais espaços de reflexão durante o desenvolvimento das atividades. Já o professor E1 acredita que realizar momentos de reflexão com os alunos é "muito difícil porque eles não [...] tá ali as portas de terminar o ano, é só formatura, ninguém não quer nem saber mais, a última semana não se quer nem se falar em aula [...] é um pouco complicado". Isso revela uma visão limitada do processo de reflexão integrado às experiências educacionais vivenciadas na disciplina e a necessidade de se pensar no processo de aprendizagem a partir dos quatro estágios do ciclo de AE de Kolb (1984).

Assim como Jiji et al. (2015) constataram em seu estudo que o desenvolvimento de projetos interdisciplinares é desafiador, evidenciando a grande demanda por professores experientes e dedicados das mais diversas disciplinas. Os professores devem ser preparados e estar dispostos a orientar grupos de alunos de maneira a ir além de suas fronteiras disciplinares habituais. Este desafio é latente na iniciativa estudada, uma vez que todos os entrevistados relatam a dificuldade no trabalho em conjunto dos professores para possibilitar o diálogo entre as áreas. Apesar de ainda existir componentes comportamentais e curriculares que dificultam este processo de ensino-aprendizagem ativo, como a necessidade de docentes dispostos e engajados com a causa e o desafio destes em trabalhar de maneira multidisciplinar em uma lógica de integração dos saberes, a iniciativa está evoluindo e se constituindo frente ao corpo docente e discente.

\section{Percepção Discente}

Inicialmente, faz-se necessário apresentar a configuração das turmas investigadas, a partir de dados coletados com os alunos participantes da pesquisa, de forma que o entendimento dos resultados obtidos possa ser completo. Na Tabela 1 apresentam-se os dados de perfil dos estudantes separados por turmas, Projeto Interdisciplinar 1 (PI 1), que corresponde aos alunos no $3^{\circ}$ ano do curso e Projeto Interdisciplinar 2 (PI 2 ) referente ao $4^{\circ}$ ano do curso. 
Tabela 1 Dados do perfil dos estudantes

\begin{tabular}{|c|c|c|c|}
\hline & & $\begin{array}{c}\text { Projeto Inter- } \\
\text { disciplinar } 1\end{array}$ & $\begin{array}{c}\text { Projeto Inter- } \\
\text { disciplinar } 2\end{array}$ \\
\hline \multirow{2}{*}{ Gênero } & Feminino & $96 \%(24)$ & $85 \%$ (17) \\
\hline & Masculino & $4 \%(01)$ & $15 \%(03)$ \\
\hline \multirow{4}{*}{ Idade } & 16 anos & $28 \%(07)$ & - \\
\hline & 17 anos & $64 \%(16)$ & $40 \%(08)$ \\
\hline & 18 anos & $8 \%(02)$ & $50 \%(10)$ \\
\hline & 19 anos & - & $10 \%(02)$ \\
\hline \multirow{2}{*}{$\begin{array}{l}\text { Já estudou } \\
\text { sustentabilidade? }\end{array}$} & Não & - & 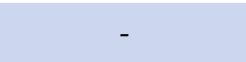 \\
\hline & Sim & $100 \%(25)$ & $100 \%(20)$ \\
\hline
\end{tabular}

Fonte: Elaborado pelos autores.

Para além dos dados sociodemográficos apresentados, no que tange ao contato com sustentabilidade, a totalidade dos alunos diz já ter estudado a temática. Ao serem questionados onde e quando estudaram sobre a sustentabilidade, a maioria, em ambas as turmas, afirmou ter sido no $3^{\circ}$ ano do ensino médio, no IFRS Campus Canoas na disciplina Projeto Interdisciplinar 1. No que tange o conhecimento prévio dos estudantes, quando questionados a respeito de o que entendem por sustentabilidade, as respostas são evidenciadas na Figura 6. 
Figura 6 Respostas alunos Projeto Interdisciplinar "O que é sustentabilidade?"

\begin{tabular}{|c|c|c|c|}
\hline & $\begin{array}{c}\% \\
\text { alunos }\end{array}$ & $\begin{array}{c}\text { Atrelam o } \\
\text { conceito de } \\
\text { Sustentabili- } \\
\text { dade ao... }\end{array}$ & Exemplos \\
\hline \multirow{6}{*}{ PI 1} & \multirow[t]{2}{*}{$44 \%$} & \multirow{2}{*}{ 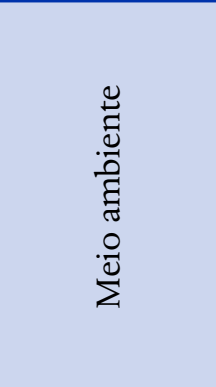 } & $\begin{array}{l}\text { A10 - Sustentabilidade é como cuidamos do } \\
\text { meio ambiente separando o lixo, reciclando e } \\
\text { agindo de forma que não prejudique o meio } \\
\text { ambiente. }\end{array}$ \\
\hline & & & $\begin{array}{l}\text { A25 - Para mim, é conhecer e agir de forma } \\
\text { positiva com o ciclo das coisas no meio am- } \\
\text { biente. }\end{array}$ \\
\hline & \multirow{2}{*}{$36 \%$} & \multirow{2}{*}{ 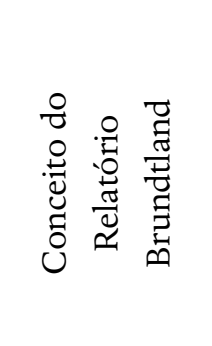 } & $\begin{array}{l}\text { A5 - Suprir as necessidades humanas atuais, } \\
\text { sem que as gerações futuras saiam prejudica- } \\
\text { das. }\end{array}$ \\
\hline & & & $\begin{array}{l}\text { A22 - Sustentabilidade é um conjunto de prá- } \\
\text { ticas que visam a utilização dos recursos sem } \\
\text { comprometer as geraçôes futuras. }\end{array}$ \\
\hline & \multirow[t]{2}{*}{$20 \%$} & \multirow{2}{*}{ 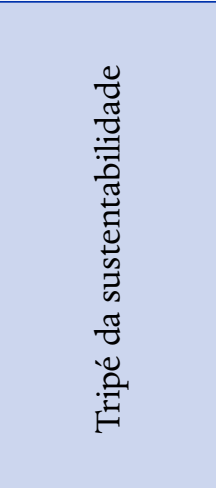 } & $\begin{array}{l}\text { A8 - Levar em conta os aspectos econômico, } \\
\text { social e ambiental, não prejudicando nenhu- } \\
\text { ma das partes. Sempre pensando no bem de } \\
\text { todas as partes e principalmente em não pre- } \\
\text { judicar o meio ambiente. }\end{array}$ \\
\hline & & & $\begin{array}{l}\text { A11 - Manter o equilíbrio entre o social, eco- } \\
\text { nômico e ambiental, dando a devida impor- } \\
\text { tância para cada um, sem dar maior impor- } \\
\text { tância a um ou outro. }\end{array}$ \\
\hline
\end{tabular}




\begin{tabular}{|c|c|c|c|}
\hline \multirow{8}{*}{ PI 2} & \multirow[t]{2}{*}{$50 \%$} & \multirow{2}{*}{ 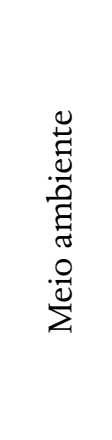 } & $\begin{array}{l}\text { B2 - É o assunto moderno que trata da pre- } \\
\text { servação da natureza e do mundo em que } \\
\text { vivemos pelo homem. Tenta transformar a } \\
\text { relação do homem com o ambiente de forma } \\
\text { que essa relação não se torne um transtorno. }\end{array}$ \\
\hline & & & $\begin{array}{l}\text { B11 - Se trata da preservação do meio ambien- } \\
\text { te e saber como direcionar operações de ma- } \\
\text { neira que afete o mínimo possível o mesmo. }\end{array}$ \\
\hline & \multirow[b]{2}{*}{$20 \%$} & \multirow{2}{*}{ 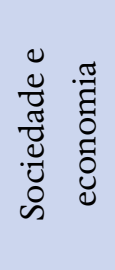 } & $\begin{array}{l}\text { B3 - É o equilíbrio entre o meio ambiente, a } \\
\text { sociedade e a economia (ou capital). }\end{array}$ \\
\hline & & & $\begin{array}{l}\text { B4 - É a capacidade de crescer economica- } \\
\text { mente em harmonia com o meio ambiente e } \\
\text { a sociedade. }\end{array}$ \\
\hline & \multirow{2}{*}{$15 \%$} & \multirow{2}{*}{ 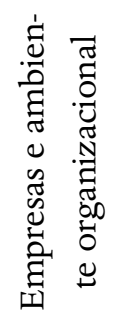 } & $\begin{array}{l}\text { B13 - É algo que não serve para um setor, mas } \\
\text { para outro talvez sirva, assim aproveitando o } \\
\text { resto, para a transformação de um produto. }\end{array}$ \\
\hline & & & $\begin{array}{l}\text { B14 - É algo necessário para se tentar preser- } \\
\text { var o mundo e trazer uma conscientização e } \\
\text { cobrança para as empresas. }\end{array}$ \\
\hline & \multirow{2}{*}{$15 \%$} & \multirow{2}{*}{ 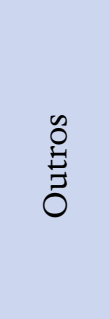 } & $\begin{array}{l}\text { B9 - Atitudes/medidas adquiridas para tornar } \\
\text { o mundo mais limpo e melhor para se viver } \\
\text { em conjunto com o avanço tecnológico. }\end{array}$ \\
\hline & & & $\begin{array}{l}\text { B17 - Usufruir de alguma coisa de forma a não } \\
\text { esgotar os recursos para que ela possa sempre } \\
\text { ser usada. }\end{array}$ \\
\hline
\end{tabular}

Fonte: Elaborado pelos autores.

A partir das respostas, é possível perceber que a maioria dos alunos, de ambas as disciplinas, apresentam uma visão de sustentabilidade bastante atrelada à dimensão ambiental. Desta forma, é interessante buscar alternativas de ampliação dessa visão, de modo a incluir as demais dimensões mencionadas por Ignacy Sachs sendo elas: social, ecológica, ambiental, 
econômica, política nacional, política internacional, cultural e territorial (SACHS, 2002). E assim, reforçar que para alcançar a sustentabilidade é preciso valorizar as pessoas, seus costumes e saberes (SACHS, 2002). Ou seja, torna-se necessário um conhecimento integrador e multidisciplinar sobre os mais variados aspectos da vida, de modo a pensar coletivamente sobre o desenvolvimento humano na Terra.

Além do conhecimento acerca do conceito de sustentabilidade, buscou-se investigar o quanto os alunos relacionam sustentabilidade com as áreas da Administração. Desta forma, questionou-se "Qual sua opinião em relação à inserção de temas relacionados com Sustentabilidade em todas as áreas da Administração (Finanças, Marketing, Produção, Gestão de Pessoas)?”. As respostas obtidas podem ser observadas a seguir, na Figura 7. 
Figura 7 Respostas alunos "Qual sua opinião em relação à inserção de temas relacionados com Sustentabilidade em todas as áreas da Administração?”

\begin{tabular}{|c|c|c|c|}
\hline & $\begin{array}{c}\% \\
\text { alunos }\end{array}$ & $\begin{array}{l}\text { Consi- } \\
\text { deram }\end{array}$ & Exemplos \\
\hline \multirow{2}{*}{ PI 1} & $68 \%$ & $\begin{array}{c}\text { Muito } \\
\text { relevante }\end{array}$ & $\begin{array}{l}\text { A1 - A administração está diretamente ligada a questões } \\
\text { econômicas e a economia e a sustentabilidade devem } \\
\text { andar juntas. Nos dias atuais é de extrema importância } \\
\text { que os gestores tenham um pensamento sustentável } \\
\text { voltado para todos os processos do negócio. }\end{array}$ \\
\hline & $32 \%$ & Relevante & $\begin{array}{l}\text { A16 - Penso que o assunto é pertinente, e que se to- } \\
\text { dos tivessem acesso a este conhecimento, tanto de for- } \\
\text { ma obrigatória (no caso da inserção nas áreas de adm) } \\
\text { como de maneira opcional, pois muito do que se vê que } \\
\text { ocorre de errado neste tema é por falta de instrução. }\end{array}$ \\
\hline \multirow{4}{*}{ PI 2} & \multirow[t]{2}{*}{$40 \%$} & \multirow{2}{*}{$\begin{array}{c}\text { Muito } \\
\text { relevante }\end{array}$} & $\begin{array}{l}\text { B4 - Acredito que a sustentabilidade deva estar inte- } \\
\text { grada a todas as áreas da administração para poder ter } \\
\text { reflexos positivos no mundo, já que a administração é } \\
\text { uma ciência cada vez mais presente e necessária. }\end{array}$ \\
\hline & & & $\begin{array}{l}\text { B19 - Pois como administradores devemos entender } \\
\text { nosso papel na sociedade e meio ambiente adequando } \\
\text { nossos valores e condutas para a sustentabilidade. }\end{array}$ \\
\hline & \multirow[t]{2}{*}{$60 \%$} & \multirow[t]{2}{*}{ Relevante } & $\begin{array}{l}\text { B1 - Não há como uma empresa ser completamente } \\
\text { sustentável, pois suas atividades não são todas sustentá- } \\
\text { veis, no entanto, é importante para a empresa realizar } \\
\text { suas atividades mesmo com poucos recursos, além de } \\
\text { não prejudicar o meio ambiente em que está inserida. }\end{array}$ \\
\hline & & & $\begin{array}{l}\text { B7 - É mais relevante em algumas áreas do que outras, } \\
\text { mas considero um tema muito importante de ser lem- } \\
\text { brado e relacionado nas matérias. }\end{array}$ \\
\hline
\end{tabular}

Fonte: Elaborado pelos autores.

Por fim, o último questionamento feito aos alunos foi "Em relação à sua formação, você acredita que o tema Sustentabilidade é:" as respostas são demonstradas na Figura 8. 
Figura 8 Respostas alunos em relação à sua formação, você acredita que o tema Sustentabilidade é.

\begin{tabular}{|l|l|l|}
\multicolumn{2}{|c}{$\%$} \\
\multicolumn{1}{|c|}{ alunos }
\end{tabular}

Fonte: Elaborado pelos autores. 
Diante do exposto, é possível perceber que por mais que os estudantes sejam bastante jovens, com idade entre 17 e 18 anos, já há indícios da incorporação da sustentabilidade em sua formação. Como já afirmavam Wals e Jickling (2002), o ensino da sustentabilidade está atrelado ao desenvolvimento de conhecimentos, capacidades e habilidades que possibilitem que os alunos tenham compreensão acerca do mundo complexo do qual fazem parte. A partir dos dados apresentados é possível notar que isto é contemplado na iniciativa estudada. Além disso, a maioria dos alunos considera importante que a temática sustentabilidade seja integrada ao ensino da Administração, pois representa uma dimensão importante na formação dos profissionais que irão atuar nas empresas. No entanto, ainda é necessário evoluir na compreensão do conceito de sustentabilidade, de maneira a abranger todas as suas dimensões. 


\section{DISCUSSÃO DOS RESULTADOS}

O contexto geral para a criação da iniciativa, as disciplinas Projeto Interdisciplinar 1 e 2, baseia-se em uma preocupação essencial com a integração curricular, aliada à preocupação com a insustentabilidade do sistema de desenvolvimento atual. Isso culminou na adoção de metodologias de ensino que, associadas, poderiam contribuir com a busca pela integração da teoria com a prática, incentivando os alunos a serem sujeitos transformadores de suas realidades por meio da aplicação dos saberes desenvolvidos durante o curso. Ao utilizar abordagens participativas, inovadoras e interdisciplinares, emerge a necessidade de trabalhar com crenças e premissas diferentes das visões reducionistas e mecanicistas enfatizadas nas abordagens tradicionais de ensino.

Para Kolb (1984), o modelo de aprendizagem consiste em um sistema ou pacote completo de exercícios e teorias que possibilita que os alunos passem por todas as fases do processo de aprendizagem com base na experiência. Na Figura 7 evidenciam-se como as quatro fases deste sistema que são identificadas na iniciativa Projeto Interdisciplinar 1, com base no modelo desenvolvido por Krakauer, Serra e Almeida (2017). A etapa inicial do ciclo de aprendizagem experiencial identificada na disciplina PI 1 configura-se no momento "conhecer", no qual os alunos têm contato com a teoria. Esta etapa compreende atividades em que o docente transmite conhecimentos relativos aos conceitos de conteúdos como: Organizações, sociedade e meio ambiente; Sustentabilidade e as Organizações; Educação Ambiental; Empreendedorismo individual e coletivo; Inovação social e Organizações Inovadoras Sustentáveis. O desenvolvimento das aulas ocorre a partir de aulas expositivo-dialogadas com auxílio de quadro e dispositivos audiovisuais, pelos quais a docente responsável procura envolver os estudantes na aula.

Na segunda etapa do ciclo, que compreende o momento "explorar", os discentes são estimulados a relacionar a teoria com a prática, discutindo novas possibilidades e diferentes contextos. Nessa etapa, os mesmos devem mapear e levantar um problema socioambiental presente na realidade deles, para, posteriormente, envolver-se no momento "realizar". Na terceira 
etapa, os estudantes se envolvem na elaboração de um projeto de pesquisa sobre a temática do problema previamente levantado.

Por fim, a última etapa do ciclo consiste no momento "observar", na qual os estudantes devem refletir sobre a experiência, em seus diversos aspectos. Atualmente, não há uma atividade formalizada para este momento, o que evidencia uma grande lacuna, uma vez que para Kolb (1984) uma atividade só é considerada uma experiência se há uma reflexão sobre o que foi vivenciado. É neste momento que os indivíduos sentem e pensam sobre o que acabaram de fazer. Assim, torna-se importante planejar atividades que busquem valorizar este momento, como por exemplo, a realização de autoavaliação, avaliação do grupo e da própria disciplina.

Figura 9 Ciclo aprendizagem experiencial Projeto Interdisciplinar 1

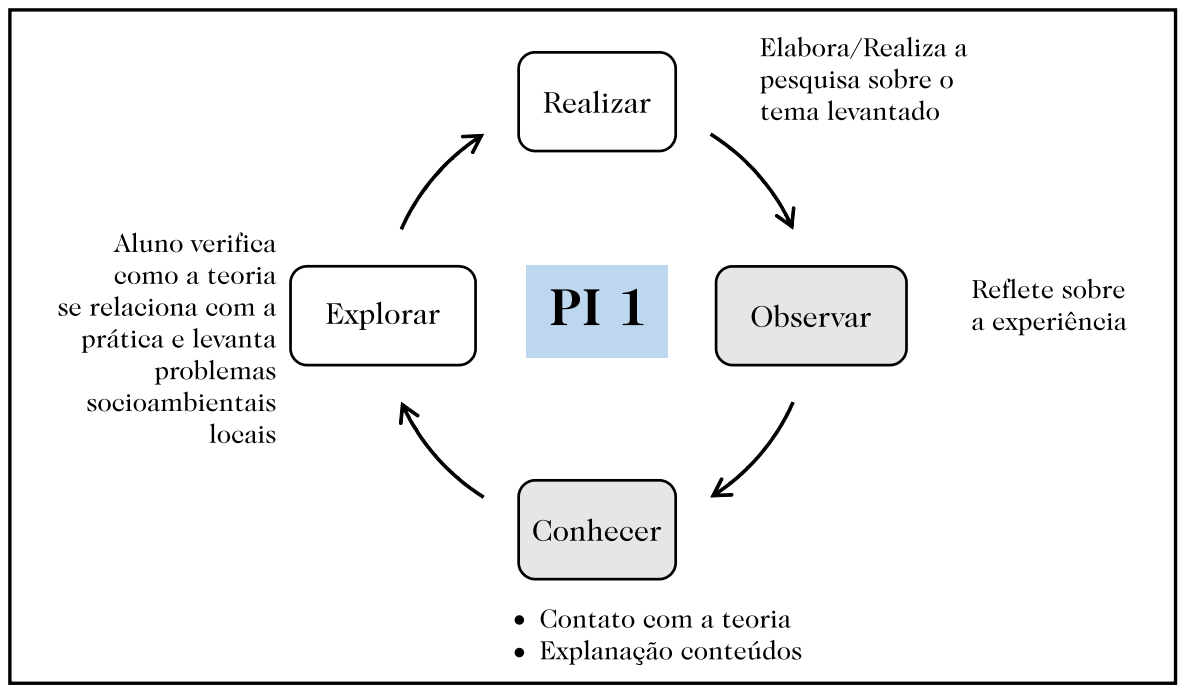

Fonte: Elaborado pelos autores.

Ao considerar que a aprendizagem é um processo em espiral, conforme entendido por Dewey (1929), no qual as experiências anteriores condicionam experiências presentes e futuras, destaca-se que a vivência da disciplina PI 1 está intimamente relacionada àquela desenvolvida no PI 2, representada na Figura 10. 
Figura 10 Ciclo aprendizagem experiencial Projeto Interdisciplinar 2

Alunos verificam como a prática se relaciona com a experiência vivenciada no desenvolvimento da pesquisa e propõem a criação de um produto ou serviço com o objetivo de minimizar o problema identificado

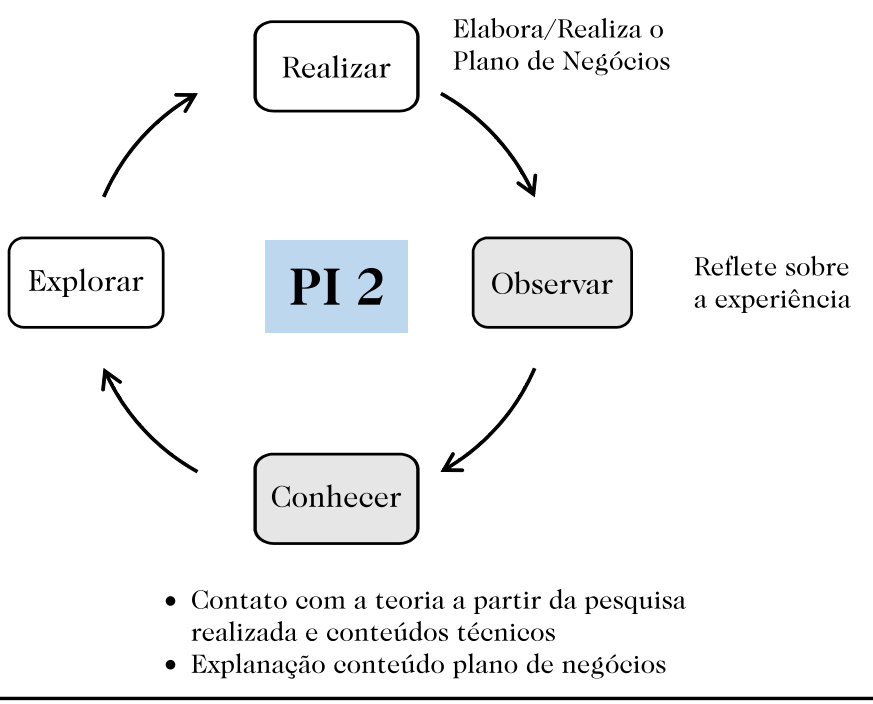

Fonte: Elaborado pelos autores.

Assim como ocorre no PI 1, o ciclo de aprendizagem experiencial da disciplina Projeto Interdisciplinar 2 inicia pelo momento "conhecer", no qual os estudantes têm contato com a teoria acerca de conteúdos como: Empreendedorismo, inovação tecnológica e social, cooperação; Empreendimentos solidários e; Etapas de elaboração de plano de negócios. A partir disso, inicia-se o momento "explorar" no qual os estudantes deverão relacionar a teoria vista no PI 1 e PI 2 com a prática. Para isso, solicita-se que os mesmos pensem no desenvolvimento de um produto ou serviço com o objetivo de apresentar uma solução ou minimizar o problema identificado no PI 1.

Na sequência, no momento "realizar" os discentes deverão elaborar um plano de negócio sustentável da organização que irá fornecer o produto ou serviço criado. Deste modo, trabalha-se com os conteúdos técnicos da Administração e com o desenvolvimento da criatividade para propor soluções sustentáveis. Por fim, assim como PI 1, para encerrar o ciclo, é necessário oportunizar momentos para que os estudantes pensem e reflitam 
sobre a experiência de modo a observar os detalhes, questionando conceitos e teorias. Para Harvey, Coulson e McMaugh (2016) esse processo de refletir para tentar entender a teoria resulta em uma mudança na estrutura mental, oportunizando que o indivíduo desenvolva diferentes maneiras de pensar. Assim, a AE se fortalece como uma ferramenta no ensino da sustentabilidade, uma vez que possibilita que o aluno desenvolva pensamento independente com novas perspectivas e visões de mundo. 


\section{CONSIDERAÇÕES FINAIS}

O presente estudo teve por objetivo analisar a capacidade contributiva da aprendizagem experiencial para a educação para a sustentabilidade em uma iniciativa interdisciplinar desenvolvida no ensino de gestão. A partir dos dados coletados e, conforme retratado nas respostas, nota-se que a disciplina apresenta importante contribuição no desenvolvimento de consciência e conhecimento acerca da temática da sustentabilidade. No entanto, ainda é possível perceber a necessidade de valer-se mais das dimensões de ação do modelo de aprendizagem experiencial para abordar o tema de maneira mais prática e, assim, desenvolver competências para sustentabilidade nos alunos, fazendo com que os mesmos de fato as incorporem nas suas ações diárias. Conquanto, pode-se notar que, apesar de se manifestar de maneira mais superficial, houve o desenvolvimento crítico, visão sistêmica, perspectiva de futuro, autonomia e senso de responsabilidade nos discentes que participaram da iniciativa.

No decorrer do percurso, limitações da pesquisa foram observadas, a saber: no que tange ao número de docentes pesquisados, que não abrangeu todos os docentes do curso em questão e; a coleta de dados com discentes foi limitada ao questionário, o que não possibilitou ter uma profundidade em detalhes nos dados coletados.

Com base na abordagem teórica e nos resultados apresentados, como sugestão de pesquisas futuras, identificou-se a necessidade de investigar, posteriormente, estes alunos como egressos do curso, a fim de identificar de que forma os conceitos foram apropriados pelos ex-alunos. Indica-se, ainda, um estudo mais profundo com os docentes em relação às melhores maneiras de incluir a sustentabilidade tanto na formação básica quanto na técnica.

Também, seria interessante explorar o desenvolvimento de competências para sustentabilidade em outros níveis de ensino como superior e pós-graduação. Sugere-se, ainda, que outras iniciativas existentes sejam estudadas à luz da aprendizagem experiencial, de modo a possibilitar o fortalecimento da $\mathrm{AE}$ na promoção da EpS a partir de diferentes evidências da 
EDUCANDO PARA O DESENVOLVIMENTO SUSTENTÁVEL POR MEIO DA INTERDISCIPLINARIDADE: CONTRIBUIÇÕES DA APRENDIZAGEM EXPERIENCIAL NO ENSINO DE GESTÃO

realidade. Por fim, replicar o estudo em uma instituição de ensino privada torna-se interessante para que se possa traçar um paralelo entre os resultados obtidos nos diferentes contextos. 


\section{REFERÊNCIAS}

ALVES, N. B.; TOMETICH, P. Teoria da Aprendizagem Experiencial e Design Thinking para Criação de uma Feira de Sustentabilidade. In: XL Encontro da ANPAD - EnANPAD, 2016.

BADEN, D.; PARKES, C. Experiential learning: inspiring the business leaders of tomorrow. Journal of Management Development, v. 32, n.3, p. 295-308, 2013. DOI: $10.1108 / 02621711311318283$

BERCHIN, I. I. et al. The importance of international conferences on sustainable development as higher education institutions' strategies to promote sustainability: A case study in Brazil. Journal of Cleaner Production, v.171, p. 756-772, 2018. DOI: https: / doi.org/10.1016/j.jclepro.2017.10.042

BOECHAT, C. B.; GRASSI, M. R. Bases da educação em sustentabilidade em uma escola de negócios. Caderno de Ideias, Nova Lima, p. 1-15, dez., 2005.

BRUNDIERS, K.; WIEK, A. Do We Teach What We Preach? An International Comparison of Problem- and Project-Based Learning Courses in Sustainability. Sustainability. v.5, 2013. DOI: $10.3390 /$ su5041725

BRUNNQUELL, C.; BRUNSTEIN, J.; JAIME, P. Education for sustainability, critical reflection and transformative learning: professors' experiences in Brazilian administration courses. International Journal of Innovation and Sustainable Development. v. 9, 2015. DOI: 10.1504 / IJISD.2015.071858

CARS, M.; WEST, E. E. Education for sustainable society: attainments and good practices in Sweden during the United Nations Decade for Education for Sustainable Development (UNDESD). Environment, Development and Sustainability, 2014. DOI: 10.1007/ s10668-014-9537-6

CORSCADDEN, K. W; KEVANY, K. The TREEhouse: A hybrid model for experiential learning in environmental education. Applied Environmental Education \& Communication, feb., 2017. DOI: 10.1080/1533015X.2017.1282334

DEWEY, J. Experience and nature. London: George Allen \& Unwin, 1929.

DOWN, L. Addressing the challenges of mainstreaming education for sustainable development in higher education. International Journal of Sustainability in Higher Education, v. 7, n. 4, p. 390-399, 2006. https: / / doi.org/10.1108/14676370610702190

DUBEY, R.; GUNASEKARAN, A.; DESHPANDE, A. Building a comprehensive framework for sustainable education using case studies. Industrial and Commercial Training, v. 49, n. 1, p. 33-39, 2017. https:// doi.org/10.1108/ICT-08-2016-0051

ELKINGTON, J. Cannibals with forks: the triple bottom line of 21st century business. Oxford: Capstone, 1999. 
FERREIRA, M.; LOGUECIO, R. de Q. A Análise de Conteúdo como Estratégia de Pesquisa Interpretativa em Educação em Ciências. Revelli - Revista De Educação, Linguagem e Literatura, v. 6, n.2, p. 33-49, outubro, 2014.

FIGUEIRÓ, P. S.; RAUFFLET, E. Sustainability in higher education: a systematic review with focus on management education. Journal of Cleaner Production, v. 106, p. 22-33, 2015.

GIL, A. C. Como elaborar projetos de pesquisa. $6^{\text {a }}$ ed. São Paulo: Atlas, 2017.DOI: https:// doi.org/10.1016/j.jclepro.2017.10.042

HARVEY, M.; COULSON, D.; MCMAUGH, A. Towards a theory of the Ecology of Reflection: Reflective practice for experiential learning in higher education. Journal of University Teaching \& Learning Practice, v.13, n.2, 2016.

HOWLETT, C.; FERREIRA, J.; BLOMFIELD, J. Teaching sustainable development in higher education: building critical, reflective thinkers through an interdisciplinary approach. International Journal of Sustainability in Higher Education, v. 17, 3, 2016. DOI: 10.1108/IJSHE-07-2014-0102

JACOBI, P. R.; RAUFFLET, E.; ARRUDA, M. P. de. Educação para a sustentabilidade nos cursos de Administração: Reflexão sobre paradigmas e práticas. RAM, Rev. Adm. Mackenzie, v. 12, n. 3, Edição Especial, São Paulo, SP, maio/jun, 2011. DOI: 10.1590/S167869712011000300003

JIJI, L.M.; SCHONDELD, I. S.; SMITH, G. A. Capstone interdisciplinary team project: a requirement for the MS in sustainability degree. International Journal of Sustainability in Higher Education, v. 16, n.2, p. 187-199, 2015. DOI: 10.1108/IJSHE-02-2013-0015

KOLB, A. Y.; KOLB, D. A. Learning Styles and Learning Spaces: Enhancing Experiential Learning in Higher Education. Academy of Management Learning \& Education, v. 4,n. 2, p.193-212, jun., 2005. DOI: 10.5465/AMLE.2005.17268566

KOLB, D. A. Experiential learning: experience as the source of learning and development. Englewood Cliffs, NJ: Prentice Hall, 1984

KRAKAUER, P. V. de C.; SERRA, F. A. R.; ALMEIDA, M. I. R. de. Using experiential learning to teach entrepreneurship: a study with Brazilian undergraduate students. International Journal of Educational Management, v. 31, n. 7, p.986-999, 2017. DOI: 10.1108/ IJEM-09-2016-0189

LEAL FILHO, W. Education for Sustainable Development in Higer Education: Reviewing Needs. Transformative Approaches to Sustainable Development at Universities. Springer, p.3-12, 2015. DOI: 10.1007/978-3-319-08837-2

MINAYO, M. C. de S. O desafio do conhecimento: pesquisa qualitativa em saúde. Rio de Janeiro, 2004.

ONU. Transformando Nosso Mundo: A Agenda 2030 para o Desenvolvimento Sustentável, 2015. . Disponível em: < https: / / nacoesunidas.org/wp-content/uploads / 2015/10/agenda2030-pt-br.pdf > . Acesso em 18 de Março de 2017. 
PALMA, L.C.; ALVES, N.B.; SILVA, T.N. da. E ducação para a sustentabilidade: a construção de caminhos no Instituto Federal de Educação, Ciência e Tecnologia do Rio Grande do Sul (IFRS). RAM, Rev. Adm. Mackenzie, v. 14, n. 3, Ed. Especial, São Paulo, May/ Jun, 2013. DOI: 10.1590/S1678-69712013000300005.

ROWE, D. Education for a sustainable future. Science, p.317-323, 2007.

SACHS, I. Caminhos para o Desenvolvimento Sustentável. Rio de Janeiro: Garamond, 2002 .

SAMPIERI, R. H.; COLLADO, C. F.; LUCIO, M. P. B. Metodologia de pesquisa. 5 ed. Porto Alegre: Penso, 2013.

SILVA, M.E. da. et al. Um espelho, um reflexo! A Educação para a Sustentabilidade como subsídio para uma tomada de decisão consciente do administrador. Ram, Rev. Adm. Mackenzie, v. 14, n. 3, Edição Especial, São Paulo, maio/jun, 2013. DOI: 10.1590/S167869712013000300007

TILBURY, D. ESD: An expert review of processes and learning. Paris: UNESCO, 2011.

THOMAS, I.; HEGARTY, K.; HOLDSWORTH, S. The Education for Sustainability Jig-Saw Puzzle: Implementation in Universities. Creative Education, v.3, special issue, p.840-846, 2012.

UNESCO. Década da Educação das Nações Unidas para um Desenvolvimento Sustentável, 2005-2014: documento final do esquema internacional de implementação.Brasília, 2005.

UNESCO. Teaching and Learning for a Sustainable Future: a multimedia teacher education programme. Disponível em: < http://www.unesco.org/education/tlsf/index. html > . Access in: february 2017. Disponível em: <http:/ / www.dominiopublico.gov.br/ download/texto/ ue000054.pdf> Acesso em: 22 de Março de 2017.

VASCONCELOS, K. C. de A.; JUNIOR, A. da S.; SILVA, P. de O. M. da. Educação gerencial para atuação em ambientes de negócios sustentáveis: desafios e tendências de uma escola de negócios brasileira. Ram, Rev. Adm. Mackenzie, v.14, n.4, São Paulo, jul./ ago, 2013. DOI: $10.1590 /$ S1678-69712013000400003

WALS, A.E.J.; JICKLING, B. "Sustainability" in higher education: from doublethink and newspeak to critical thinking and meaningful learning. Higher Education Policy, v.15, 2002. DOI: $10.1016 /$ S0952-8733(02)00003-X

YIN, R. K. Estudo de caso: planejamento e métodos. $5^{\text {a }}$ ed. Porto Alegre: Bookman, 2015.

WRIGHT, T. S. A. Feeling Green: Linking Experiential Learning and University Environmental Education. Higher Education Perspectives, 2(1), p.73-90, 2006.

Beneficiário de auxílio financeiro da Coordenação de Aperfeiçoamento de Pessoal de Nível Superior. 


\section{DADOS DOS AUTORES}

\section{NATHÁLIA RIGUI TRINDADE nathaliariguitrindade@gmail.com}

Doutoranda em Administração pela UFSM

Instituição de vinculação: Universidade Federal de Santa Maria

Santa Maria/RS - Brasil

Áreas de interesse em pesquisa:Administração; Educação; Estratégia, Sustentabilidade, Internacionalização.

Av. Roraima, 1000, Cidade Universitária, Prédio 74-C Camobi Santa Maria/RS 97105-900

\section{MARCELO TREVISAN marcelotrevisan@smail.ufsm.br}

Doutor em Administração pela UFRGS

Instituição de vinculação: Universidade Federal de Santa Maria

Santa Maria/RS - Brasil

Áreas de interesse em pesquisa: Educação para Sustentabilidade; Sustentabilidade Socioambiental.

\section{ÉRICA SANTINI DE LIMA ericasantini92@hotmail.com}

Graduanda em Administração pela UFSM

Instituição de vinculação: Universidade Federal de Santa Maria

Santa Maria/RS - Brasil

Áreas de interesse em pesquisa: Administração, Logística, Finanças.

\section{RODRIGO REIS FAVARIN rodrigo.favarin@hotmail.com}

Doutorando em Administração pela UFSM

Instituição de vinculação: Universidade Federal de Santa Maria

Santa Maria/RS - Brasil

Áreas de interesse em pesquisa: Administração, Sustentabilidade, Inovação, Estratégia. 